\title{
Pharmacoeconomic Study
}

National Cancer Institute

\section{Source}

National Cancer Institute. Pharmacoeconomic Study. NCI Thesaurus. Code C39493.

A study that assesses the value associated with a given drug in therapeutic and economic terms. This type of study is multidisciplinary in nature and takes into consideration the social and economic costs (resource utilization costs including direct, indirect, and intang ible costs) of drug therapy in addition to its direct therapeutic benefits. Analyses relate the difference in therapeutic benefits to the difference in costs between treatment alternatives. 